\title{
A study of incidence of Pulmonary Nocardiasis at tertiary health care centre in Dhule
}

\author{
Adchitre Hitesh Ramesh ${ }^{1}$, D B More ${ }^{2 *}$, Megha Jaraje ${ }^{3}$
}

$\left\{{ }^{1}\right.$ Associate Professor, Department Microbiology $\}$ \{ ${ }^{2}$ Ex-Associate Professor, Department of Chest $\}\left\{{ }^{3}\right.$ Medical Officer, RNTCP $\}$

SBH Government Medical College, Dhule, Maharashtra, INDIA.

Email: dbmore62@gmail.com

\begin{abstract}
Background: Nocardiosis is an infectious disease caused by Nocardia, which is a gram-positive bacillus with a branching hyphae morphology. It is a disease affecting different organs of the body. It is most commonly observed in patients with immunosuppression. Aim and objective: To study the incidence of pulmonary Nocardiarsis in and around Dhule Methodology: Present study was a prospective study carried out on samples received from patients with suspected nocardiasis. Samples were collected from the patients with diabetes and asthma and taking steroids for longer time complaining of respiratory symptoms. Samples received were Sputum, gastric aspirate, broncho alveolar lavage (BAL). All samples were examined by gram staining microscopically. For isolation of Nocardia Lowenstein Jensen (LJ) slopes and Sabouraud's Dextrose agar (SDA) were used. Data was analysed with appropriate statistical tests. Results and discussion: out of all, 11 samples showed culture positive on LJ medium. The incidence of Pulmonary Nocardiasis was $1.35 \%$. Elderly males in the age group of $41-80$ years were commonly affected. Out of $11,7(63.64 \%)$ patients were having immunocompromised state.
\end{abstract}

Key Word: Pulmonary Nocardiasis.

*Address for Correspondence:

Dr D B More, Chhakarbardi Parisar Near Residensy Park Hotel, Dhule, Maharashtra, INDIA.

Email: dbmore62@gmail.com

Received Date: 09/11/2019 Revised Date: 12/12/2019 Accepted Date: 02/01/2020

DOI: https://doi.org/10.26611/10081531

This work is licensed under a Creative Commons Attribution-NonCommercial 4.0 International License. $(\boldsymbol{C c})$ EY-NC

\begin{tabular}{|l|l|}
\hline \multicolumn{2}{|c|}{ Access this article online } \\
\hline Quick Response Code: & Website: \\
\hline & www.medpulse.in \\
\cline { 2 - 2 } & \\
\hline
\end{tabular}

\section{INTRODUCTION}

The Nocardia is genus of aerobic gram-positive bacteria. It causes a range of infectious diseases, including isolated pulmonary and skin infections and disseminated disease. ${ }^{1}$ Pulmonary nocardiasis is most commonly observed disease among all forms. Pulmonary nocardiasis presents as subacute or chronic disease. It's presentation mimick lung cancer or other pulmonary infections like bacterial pneumonia or mycosis. Manifestations of the disease range from cutaneous infection caused by traumatic inoculation of the organism in a normal host to severe pulmonary or central nervous system (CNS) infections especially in an immunocompromised host. $^{2}$ Histopathologically, Nocardia is viewed as a branching, filamentous, grampositive organism. Nocardia is typically weak acid-fast positive on microscopy with staining. There are more than 90 Nocardia species, at least 33 of which cause disease in humans. ${ }^{3}$ Infections from nocardia are acquired from the environment. It is found in soil, decomposing vegetation, other organic matter and water (fresh and salt water). transmission from person to person has not been reported. ${ }^{4}$ They usually cause an opportunistic infection in immunocompromised hosts especially those who are deficient in cell-mediated immunity but cases of nocardiosis have also been reported in some immunocompetent individuals. ${ }^{5}$ Risk factors for acquiring Nocardia include Alcoholism, Chronic lung disease (patients with pulmonary alveolar proteinosis), Solidorgan transplant, Use of corticosteroids, Hematological malignancy, Collagen vascular disease (lupus), Renal failure, Inflammatory bowel disease, Whipple disease and HIV. The mortality due to pulmonary nocardiosis is high 
$(14-40 \%) .{ }^{6-8}$ The course of the disease is marked by remissions and relapses. ${ }^{9}$ Various studies has been carried out in past. Very few studies were carried out on pulmonary nocardiasis. It may be because of changes in taxonomy and difficult inherent in routine identification of Nocardia strain. 10-14 With increasing number of immunocompromised patients there is increased incidence of nocardiosis. Diagnosis of Nocardiasis is very important as it has non specific symptoms and it mimicks with many respiratory conditions. Present study was carried out to find the incidence of pulmonary Nocardiasis in and around Dhule district in Maharashtra.

\section{MATERIAL AND METHODS}

Present study was a prospective study carried out in Microbiology department of tertiary health care center near Dhule. Study population was samples from patients suspected with Nocardiasis.

Inclusion Criteria: 1. Diabetic patients who are immunocompromised 2. Asthmatic patients who are taking steroids for long times. And had symptoms of pneumonia

Exclusion criteria: 1. Patients not willing to participate in the study

Study was approved by ethical committee of the institute. A valid written consent was taken from the patients after explaining study to them.

Samples were collected from the patients with diabetes and asthma and taking steroids for longer time complaining of respiratory symptoms. Samples received were Sputum, gastric aspirate, broncho alveolar lavage (BAL). Samples were processed for Nocardia in mycobacteriology laboratory. Standard isolation and identification techniques as described by the American Society of Microbiology (ASM) were used for the diagnosis of nocardial infections. ${ }^{15}$ All sampes were examined by gram staining microscopically. For isolation of Nocardia Lowenstein Jensen (LJ) slopes and Sabouraud's Dextrose agar (SDA) were used. Samples were incubated at $37^{\circ} \mathrm{C}$ for up-to six weeks and examined every alternate day for any Nocardial growth. ${ }^{16}$ Identification of nocardia was performed on the basis of microscopic morphology, colonial morphology and biochemical tests (casein, tyrosine, xanthine and urea hydrolysis. ${ }^{17}$ Data was collected with pre tested questionnaire. Data included demographic data of the patients. Clinical history and clinical examination data was collected from the respective departments where patients were admitted. If necessary investigations like complete blood count, blood suger level, liver and renal function tests were carried out. Data entered in excel sheet. Data was analysed with SPSS version 20.

\section{RESULTS}

We studied total 810 samples over a period of one year. Among these samples we found 11 samples positive for Nocardiasis. Out of all samples 8 samples showed Acid fast branching filaments. 11 samples showed culture positive on LJ medium. Culture positive on SDA were 10 and culture positive on blood agar were 7 samples. On staining and culture, LJ culture was found to be superior than SDA and Blood agar for isolation of Nocardia, we consider 11 positive patients for pulmonary nocardiasis. Thus the incidence of Pulmonary Nocardiasis was $1.35 \%$. Table 1 showed distribution of patients according to age group. Majority of the patients were from age group of 6180 years $(63.64 \%)$ followed by $41-60$ years $(27.27 \%)$. One patient was found in the age group of 21-40 years. None of the patient was from 1-20 years. Mean age of the patient was 56.6 2.7 years. Fig 1 showed sexwise distribution of patients of pulmonary nocardiasis. Out of total 11 patients 9 were male and 2 were female. Male to female ratio was 4.5:1. Table 2 showed distribution of patients according to associated co morbidities. Out of total 11 patients 4 were without any associated co morbidity. Diabetes milletus was found in $3(27.27 \%)$ patients. COPD with smoking was observed in $3(27.27 \%)$ patients. one patient had malignancy. Patients with diabetes milletus were farmers. Among the Nocardia species isolated, based on biochemical reaction, 6 were Nocardia asteroides, 2 were Nocardia brasiliensis. Nocardia farcinica Nocardia transvalensis and Nocardia nova were identified in 1 patient each. (fig 2 )

Table 1: Distribution Of Pulmonary Nocardiasis patients according

\begin{tabular}{cccc}
\multicolumn{4}{c}{ to age group } \\
\hline Sr no & Age group & No of patients & Percentage \\
\hline 1 & $1-20$ & 00 & $0 \%$ \\
2 & $21-40$ & 01 & $9.09 \%$ \\
3 & $41-60$ & 03 & $27.27 \%$ \\
4 & $61-80$ & 07 & $63.64 \%$ \\
\hline 5 & Total & 11 & $100 \%$ \\
\hline
\end{tabular}

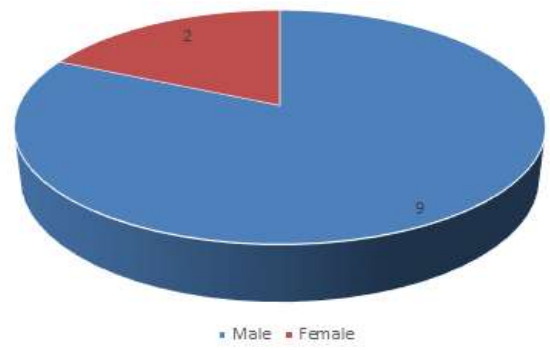

Figure 1: Distribution Of Pulmonary Nocardiasis patients according to sex

Table 2: Distribution Of Pulmonary Nocardiasis patients according to associated comorbidities 


\begin{tabular}{cccc}
\hline Sr no & $\begin{array}{c}\text { Associated co } \\
\text { morbidity }\end{array}$ & $\begin{array}{c}\text { No of } \\
\text { patients }\end{array}$ & Percentage \\
\hline 1 & Diabetes milletus & 03 & $\mathbf{2 7 . 2 7 \%}$ \\
2 & COPD with smoking & 03 & $\mathbf{2 7 . 2 7 \%}$ \\
3 & Malignancy & 01 & $9.09 \%$ \\
4 & No comorbidity & 04 & $\mathbf{3 6 . 3 7 \%}$ \\
\hline 5 & Total & 11 & $100 \%$ \\
\hline
\end{tabular}

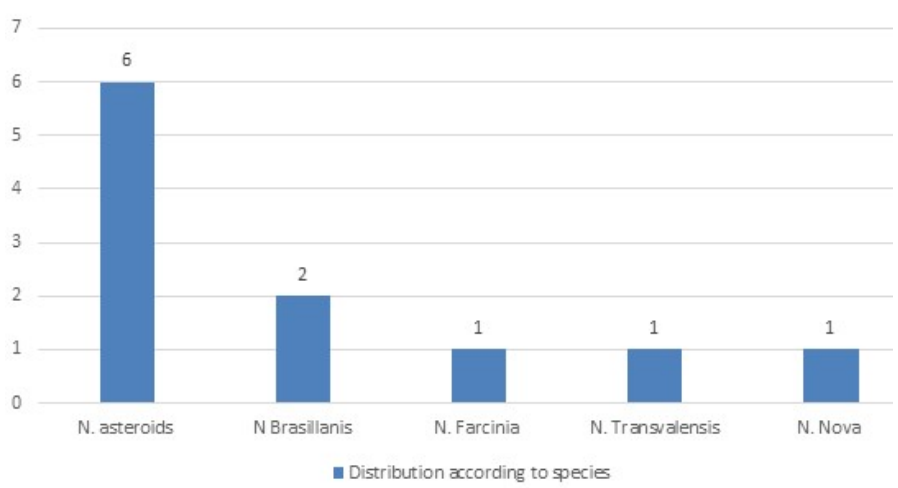

Figure 2: Distribution Of Pulmonary Nocardiasis patients according to species

\section{DISCUSSION}

In our study the incidence of Pulmonary Nocardiasis was $1.35 \%$. In a study by Shome S.K et al., ${ }^{18}$ they studied 860 patients with tuberculosis and found 32 patients were positive for nocardiarsis. Similar to our study Shivaprasad M R et al. ${ }^{19}$ found 12 cases over a period of 26 months. In our study, Majority of the patients were from age group of $61-80$ years $(63.64 \%)$ followed by $41-60$ years $(27.27 \%)$. Mean age of the patient was $56.6 \pm 2.7$ years. Similar findings were observed in A. Kageyama et al.. ${ }^{20} \mathrm{We}$ found, Out of total 11 patients 9 were male and 2 were female. Male to female ratio was 4.5:1. This was consistent with the previously published studies. ${ }^{21-23}$ The male predominance in patients with nocardiosis may be ascribed to the hormonal effects on the virulence or growth of Nocardia. In our study $63.64 \%$ patients were with comorbidities. Diabetes milletus was found in $3(27.27 \%)$ patients. COPD with smoking was observed in 3(27.27\%) patients. one patient had malignancy. These comorbidities lead to immunosuppression. Similar findings were observed in previous studies. ${ }^{11-13}$ In our study, Among the Nocardia species isolated, based on biochemical reaction, most commonly observed species was Nocardia asteroids (6/11) followed by Nocardia brasiliensis (2/11). Nocardia farcinica Nocardia trans-valensis and Nocardia nova were identified in 1 patient each. All these patients responded to tab. Septran, so sensitivity is not done in our study.

\section{CONCLUSION}

Pulmonary Nocardiasis was most commonly seen in elderly immunocompromised males with $1.35 \%$ incidence at a tertiary health care centre.

\section{REFERENCES}

1. M.A. Saubolle, D. Sussland Nocardiosis: review of clinical and laboratory experience J Clin Microbiol, 41 (2003), pp. 4497-4501

2. Brown-Elliot B, Brown J, Conville P,Wallace R Clinical and Laboratory Features of the Nocardiaspp. Based on Current Molecular Taxonomy. Clin Microbiol Rev 2006; 259-82.

3. Manikandan P, Bhaskar M, Ravathi R, Anita R, Abarna LLR, Narendran V. Isolation and antimicrobial susceptibility pattern of Nocardia among people with culture proven ocular infections attending a tertiary care eye hospital in Tamilnadu, South India. Eye 2007;21:1102-08.

4. Georghious PR and Blacklock ZM. Infection with Nocardiosis species in Queensland. A review of 102 clinical isolates. Med J Aust 1992;156: 692-7.

5. B.A. Brown-Elliott, J.M. Brown, P.S. Conville, et al.. Clinical and laboratory features of the Nocardia spp. based on current molecular taxonomy Clin Microbiol Rev, 19 (2006), pp. 259-282

6. Muñoz J, Mirelis B, Aragón LM, Gutiérrez N, Sánchez F, Español M, et al.. Clinical and microbiological features of nocardiosis 1997-2003. J Med Microbiol 2007;56(Pt 4):545-50.

7. Chedid MB, Chedid MF, Porto NS, Severo CB, Severo LC. Nocardial infections: Report of 22 cases. Rev Inst Med Trop Sao Paulo 2007;49:239-46.

8. Martínez Tomás R, Menéndez Villanueva R, Reyes Calzada S, Santos Durantez M, Vallés Tarazona JM, Modesto Alapont M, et al.. Pulmonary nocardiosis: Risk factors and outcomes. Respirology 2007;12:394-400

9. Wilson JW. Nocardiosis: Updates and clinical overview. Mayo Clin Proc 2012;87:403-7

10. R. Menéndez, P.J. Cordero, M. Santos, et al. Pulmonary infection with Nocardia species: a report of 10 cases and review Eur Respir J, 10 (1997), pp. 1542-1546

11. L. Garcia-Bellmunt, O. Sibila, I. Solanes, et al.. Pulmonary nocardiosis in patients with COPD: characteristics and prognostic factors Arch Bronconeumol, 48 (2012), pp. 280-285

12. C.H. Hui, V.W. Au, K. Rowland, et al.. Pulmonary nocardiosis re-visited: experience of 35 patients at diagnosis Respir Med, 97 (2003), pp. 709-717

13. Y.C. Chen, C.H. Lee, C.C. Chien, et al.. Pulmonary nocardiosis in southern Taiwan J Microbiol Immunol Infect (2012), 10.1016/j.jmii.2012.07.017

14. V. Pintado, E. Gómez-Mampaso, J. Fortún, et al.. Infection with Nocardia species: Clinical spectrum of disease and species distribution in Madrid, Spain, 19782001 Infection, 30 (2002), pp. 338-340.

15. Murray PR, Baron EJ, Pfaller MA, Tenover FC, Yolken RH. Manual of clinical Microbiology, $7^{\text {th }}$ edition. Washington DC: ASM press. 1999;370-98.

16. Bareja R, Jindal RC, Vohra P, Grover PS. Evaluation of various techniques for the detection of Nocardia species in clinically evident cases of pulmonary and extrapulmonary 
tuberculosis. IOSR J Dental and Med Sci (IOSR-JDMS) 2014 Jan; 13(1):Ver III 65-70.

17. Kiska DL, Hicks K, Pettit DJ. Identification of medically relevant Nocardia species with an abbreviated battery of tests. J Clin Microbiol 2002;40:1346-51.

18. Shome S.K, Upreti H.B, Singh M.M, Pamra S.P. Mycoses as-sociated with pulmonary tuberculosis. Ind $\mathrm{J}$ Tub 1976;23:64-68.

19. Shivaprakash MR, Rao P, Mandal J, et al.. Nocardiosis in a tertiary care hospital in North India and review of patients reported from India. Mycopathologia 2007;163:267-274.
20. A. Kageyama, K. Yazawa, J. Ishikawa A. et al. . Nocardial infections in Japan from 1992 to 2001 including first report of infection Nocardia transvalensis. Eur J Epidemiol 2004;19:383-389.

21. Mootsikapun P, Intarapoka B, Liawnoraset W. Nocardiosis in Srinagarind Hospital, Thailand: Review of 70 cases from 1996-2001. Int J Infect Dis 2005;9:154-8.

22. Castro JG, Espinoza L. Nocardia species infections in a large county hospital in Miami: 6 years experience. J Infect 2007;54:358-61.

Matulionyte R, Rohner P, Uçkay I, Lew D, Garbino J. Secular trends of Nocardia infection over 15 years in a tertiary care hospital. J Clin Pathol 2004;57:807-12.

\section{Source of Support: None Declared} Conflict of Interest: None Declared 